Faculdade de Ciências Econômicas UFRGS
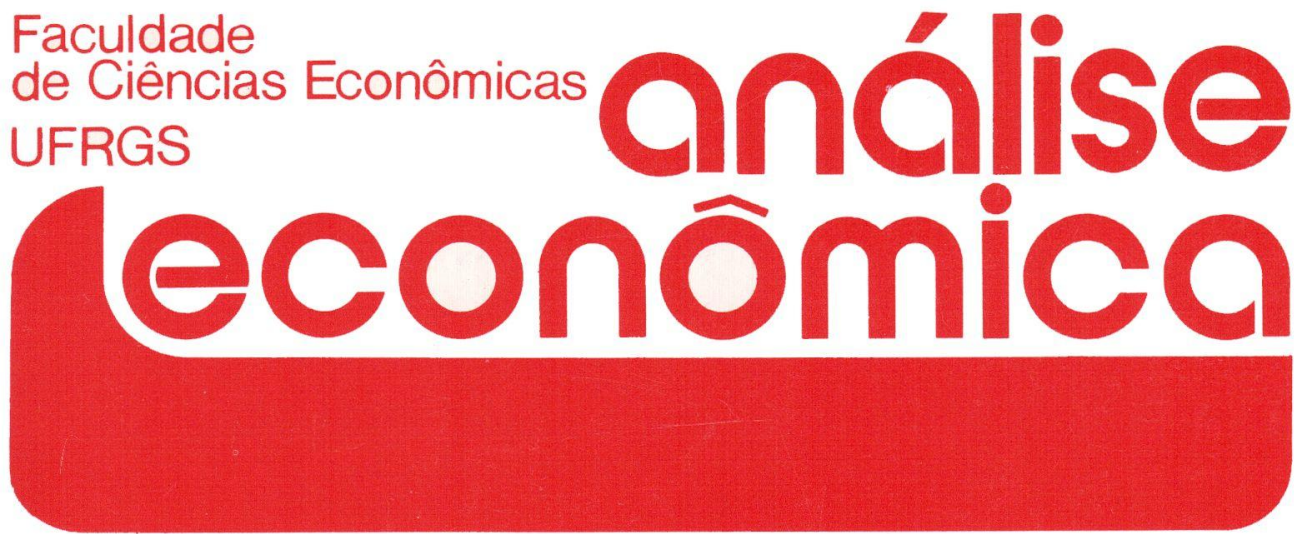

- STATE AND THE LIBERALIZATION OF THE BRAZILIAN ECONOMY

Carlos Alberto Longo

- MOEDA E CRÉDITO NA ECONOMIA BRASILEIRA: UM MODELO COM VETORES DE CORREÇÃO DE ERROS

Rolando M. Guzmán

- baSES PARA UM NOVO MOdELO DE POLítica FISCAL, PARA O BRASIL

Flávio Riani

- POR QUE OS SINOS DOBRAM? CONFLITO TRABALHISTA E SALÁRIOS DO MAGISTÉRIO PÚBLICO DO RIO GRANDE DO SUL, 1974-1991

Carlos Henrique Horn

Roberto Balau Calazans

- A POLÍtica MONETÁRIa E AS TAXAS de JUROS NO PLANO COLLOR

Lauro Lobo Burle

- DIFUSÃo E TRANSFERÊNCIA DA TECNOLOGIA DE PRODUÇÃO DE CIMENTO NO BRASIL

Maria Cristina Pereira de Melo

- SISTEMA FINANCEIRO BRASILEIRO: UMA PROPOSTA dE disCuSSÃo

Luiz Felipe Serpa

- TEORIA ECONÓMICA DO CASAMENTO E DO Divórcio

Giácomo Balbinotto Neto

- RESENHA

VARGAS: O CAPITALISMO EM CONSTRUÇÃO, DE PEDRO C. D. FONSECA

João Rogério Sanson

- LIVROS RECEBIDOS

Claudine Saldanha César
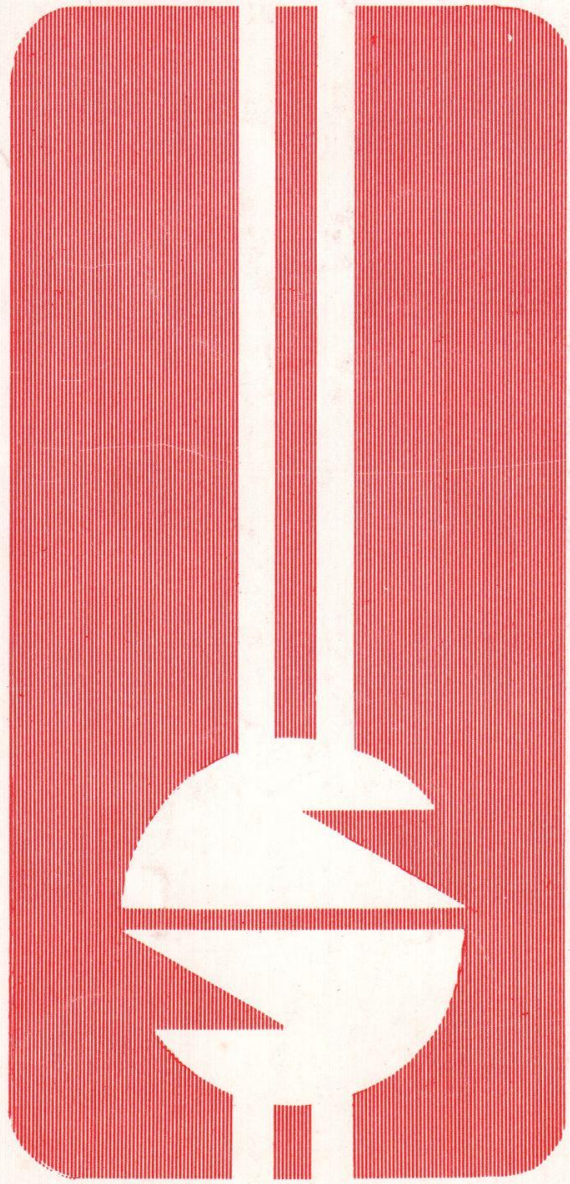
UNIVERSIDADE FEDERAL DO RIO GRANDE DO SUL

Reitor: Prof. Hélgio Henrique Casses Trindade

FACULDADE DE CIÉNCIAS ECONÔMICAS

Diretora: Prof ${ }^{a}$ Yeda Rorato Crusius

CENTRO DE ESTUDOS E PESQUISAS ECONÔMICAS

Diretor: Reinaldo Ignacio Adams

DEPARTAMENTO DE CIENNCIAS ECONÔMICAS

Chefe: Prof. Fernando Ferrari Filho

CURSO DE PÓS-GRADUAÇÃO EM ECONOMIA

Coordenador: Prof. João Rogério Sanson

CURSO DE PÓS-GRADUAÇÃO EM ECONOMIA RURAL

Coordenador: Prof. Juvir Luiz Mattuella

CONSELHO EDITORIAL: Achyles Barcelos da Costa, Aray Miguel Feldens, Atos Freitas Grawunder, Carlos Augusto Crusius, ErnaniHickmann, Fernando Ferrari Filho, João Rogério Sanson, Juvir Luiz Mattuella, Maria Imilda da Costa e Silva, Nali de Jesus de Souza, Nuno Renan Lopes de Figueiredo Pinto, Otília Beatriz Kroeĩ Carrion, Otto Guilherme Konzen, Paulo Alexaridre Spohr, Pedro Cezar Dutra Fonseca, Reinaldo Ignacio Adams, RobertsCamps Moraes, Valter José Stülp, Yeda Rorato Crusius, David Garlow (Wharton Econometrics Forecasts Association, E.U.A.), Edgar Augusto Lanzer (UFSC), Eleutério F. S. Prado (USP), Fernando Holanda Barbosa (FGV/RJ), Gustavo Franco (PUC/RJ), Joaquim Pinto de Andrade (UiNB), Juan H. Moldau (USP), Werner Baer (Univ. de Illinois, E.U.A.)

COMISSÃO EDITORIAL: Atos Freitas Grawunder, Reinaldo Ignacio Adams, Pedro Cezar Dutra Fonseca, Roberto Camps Moraes.

EDITOR: Nali Jesus de Souza

SECRETARIA: Maria Ivone de Mello (normalização), Vanete Ricacheski (revisão de textos)

FUNDADOR: Prof. Antônio Carlos Santos Rosa

Os materiais publicados na Revista Análise Econômica são de exclusiva responsabilidade dos autores. É permitida a reprodução total ou parcial dos trabalhos, desde que seja citada a fonte.

Aceita-se permuta com revistas congêneres. Aceitam-se, também, livros para divulgação, elaboração de resenhas ou recensões.

Toda correspondência, material para publicação (vide normas na $3^{a}$ capa), assinaturas e permutas devem ser dirigidos ao seguinte destinatário:

PROF. NALI DE JESUS DE SOUZA

Revista Análise Econômica

Av. João Pessoa, 52

90040-000 - PORTO ALEGRE (RS), BRASIL

Telefones: (051) 228.1633 - 224.6022 - Ramais 3348 ou 3440

FAX: (051) 225.1067 


\title{
SISTEMA FINANCEIRO BRASILEIRO: UMA PROPOSTA DE DISCUSSÃO
}

\author{
Luiz Felipe Serpa*
}

\begin{abstract}
SINOPSE
Este artigo enfoca as diferentes concepçōes sobre o papel do sistema financeiro na acumulação de capital a longo prazo na economia brasileira, reavaliando inicialmente oque $\epsilon$ aqui compreendido como vieses interpretativos estabelecidos pelas duas vertentes principais, a estatizante e a privatizante para, a seguir, buscar contribuir para a estruturação, ora em curso, de outros referenciais de üscussão sobre as perspectivas oferecidas pelo sistema financeiro à reorganização do planejamento da acumulação de capital a longó prazo na economia brasileira.
\end{abstract}

\section{INTRODUÇÃo}

Após o ciclo de inciustrialização do período 1974-1980, capitaneado por investimentos estatais, os anos oitenta delinearam um quadro de claro esgotamento da capacidade de financiamento de longo prazo da acumulação de capital no Brasil (Tavares, 1984).

Os mecaaiismos de captação da poupança compulsória, via Estado, encontravam-se política e operacionalmente inviabilizados (Pereira e Nunes, 1984), e a alternativa do capital estrangeiro encontrava obstáculos iritransponíveis na crise da dívida externa. Por outro lado, es mercados financeiros nacionais nãc dispunhanı de alternativas de financiamento de longo prazo, perpetuando, por excelência, a cultura financeira nacional, centrada em mercados de crédito voltados ao financiamento da dívida pública e ao financiamento do capital de giro e do consumo, articulados, organizacional e patrimonialmente, a mercados de capitais sem densidade e envergadura para esta tarefa, já bastante debilitados pelas sucessivas crises especulativas nos mercados bursáteis.

Assistiu-se, em meio ao impasse político e organizacional, à estagflação e à paralisia do crescimento industrial. É neste contex to que se estruturam diversas

* Economista, mestre em finanças pelo Programa de Pos-Graduação em Administração da UFRGS

\begin{tabular}{|l|l|l|l|l|}
\hline ANÁLISE ECONÔMICA & ANO 10 & N:18 & SETEMBRO/92 & P. 113-124 \\
\hline
\end{tabular}


propostas interpretativas, aqui polarizadas, grosso modo, em. duas vertentes ideologicamente antagônicas, a saber:

a) a vertente privatizante ou desregulacionista, usualmente de inspiração neoliberal ou liberal, que propugna pela desestatização, desregulamentação e internacionalização da economia como mecanismos fundamentais de equacionamento do problema, enfatiza o resgate da eficiência alocativa como eixo fundamental.

b) a vertente estatizante ou intervencionista, usualmente de inspiração socialista ou social-democrata e, mais raramente, nacional-socialista, que propugna por reformas estruturais que redirecionem o papel do Estado enquanto agente organizador em moldes distintos daqueles caracterizados pelos anos setenta $\mathrm{e}$ oitenta, enfatiza o resgate da eficiência distributiva como eixo fundamental.

Para fins de simplificação expositiva, as duas vertentes serão aqui genericamente denominadas de estatizante e privatizante.

Não nos propomos, neste trabalho, a discutir o escopo e profundidade dos paradigmas que dão lastro a estas vertentes interpretativas, mas sim pinçar alguns elementos dos subsistemas subjacentes a elas, particularmente as concepções quanto ao sistema financeiro, criticando-as de forma sucinta no que entendemos ser seus vieses interpretativos, alguns específicos, decorrentes da leitura ideológica dos fenômenos, e outros, de caráter cultural-organizacional, supra-ideológicos em diversos aspectos.

É neste corte conceitual que inserimos nossa contribuição à rediscussão do papel do sistema financeiro, resgatando alguns referenciais e sugerindo outros enfoques para a formação de novos referenciais.

\section{OS VIESES INTERPRETATIVOS}

Inicialmente, analisaremos sucintamente os três vieses interpretativos mais comuns à discussão sobre opapel do sist $\_$ma financeiro: a eficiência microeconĉmica versus eñiciência macroeconômica; eficiência alocativa versus eficiência distributiva e estoques versus fluxos.

\subsection{Eficiência Microeconômica X Eficiência Macroeconômica}

O enfoque privatizante enfatiza a eficiência do sistema financeiro tendo como parâmetro suas excepcionais taxas de retorno sobre ativos, superiores às médias internacionais.

O enfoque estatizante sustenta a ineficiência do sistema tendo como parâmetro sua incapacidade de financiar a acumulação de capital a longo prazo.

Estes enfoques, quando articulados no plano exclusivamente ideológico, assumem o caráter de mútua excludência, inviabilizando sua necessária complementaridade analítica. 
Quando ideologicamente contextualizada, a perspectiva estatizante freqüentemente ignora o extraordinário alcance e densidade operacionais atingidos pela indústria bancária. Com efeito, a fantástica malha de pontos de captação e aplicação, sua excelente distribuição geográfica, o seu aparato tecnológicoinformacional e, sobretudo, o volume de seu fluxo de capitais, tornam pouco consistente a tentativa de explicar-se a incapacidade de financiar a acumulação de capital a longo prazo como função da ineficiência organizacional do sistema financeiro.

Por outro lado, o enfoque privatizante impede a compreensão dos elementos que, necessariamente, interligam o sistema financeiro ao fenômeno inflacionário apegando-se a confortável (sob seu enfoque) mas pouco defensável idéia de que o sistema financeiro apenas traduz, nos prazos e na qualidade de suas operações, a conjuntura econômica no qual está inserido, não sendo, portanto, responsável pela inflação.

Em um passe de mágica, ignora-se a própria dinâmica do capital financeiro no Brasil. A exclusão da intermediação financeira privada no financiamento da acumulação de capital de longo prazo não é fortuita, sendo elemento essencial da própria cultura organizacional do capital financeiro nacional, que busca a eliminação do risco ďe longo prazo pela sua transferência ao Estado. O sistema financeiro é, portanto, simultaneamente agente e beneficiário maior do processo inflacionário. Este fenômeno não pode, naturalmente, ser explicado louvando-se as espectaculares taxas de retorno sobre ativos obtidas pelo sistema financeiro brasileiro.

Por outro lado, ainda que boa parte da eficiência microeconômica da indústria bancária seja o subproduto da alavancagem de inúmeras vantagens institucionais, a evolução dos referenciais tecnológicos enegociais e a concomitante substituição do dinheiro-eletrônico pelo dinheiro-informação (Motta, 1987), dificilmente poderiam ser explicadas exclusivamente em função de mudanças no quadro sócio-político. É fundamental, portanto, que não se confunda a análise da eficiência organizacional, administrativa e gerencial,com a análise macroeconômica da qualidade do financiamento oferecido pelo sistema financeiro. A primeira deve ser compreendida em função do grau de avanço tecnológico atingido pelı sistema financeiro; a segunda interpretada em função do planejamento estratégico que the é conferido, à luz da cultura organizacional do capital.

Abrangendo estas duas interpretações, poderíamos aqui sugerir que a idéia de incapacidade de financiamento a longo prazo seja substituída pela idéia de capacidade ociosa de financiamento a longo prazo do sistema.

Nesta hipótese interpretativa, a ineficiência do sistema, no financiamento da acumulação de capital a longo prazo, não pode ser negativamente correlacionada à sua eficiência microeconômica. A constatação de que as atuais estrutura e superestrutura do sistema tenham sido viabilizadas por um contexto institucional que permitia taxas de lucro excepcionais não pode impedir a compreensão de que este aparato é, agora, mais do que nunca, condição necessária (ainda que não 
suficiente) para a implementação de estratégias de financiamento a longo prazo capazes de resgatar o parque industrial.

A aceitação desta hipótese interpretativa implica sugerir o resgate do planejamento estratégico no sistema financeiro como etapa organizacional precedente ao próprio resgate do planejamento estratégico no setor industrial.

Assim referenciado, cabe identificar cautelosamente as novas relações sócio-políticas engendradas a partir do próprio sistema financeiro, advindas das profundas alterações ocorridas no metabolismo capital-trabalho, em face de um contexto tecnológico totalmente diferente em forma e conteúdo. Dentre estas alterações, destacam-se o gigantismo e a sofisticação atingidos pelos sistemas de informação, controlados pelos administradores financeiros destas instituições, cuja potencial ação artịculada teria desdobramentos imprevisíveis na organização econômica do país.

A análise destes fenômenos precisa transcender, portanto, à simples constatação neoludista de que a tecnologia, tal como em outros setores, é essencialmente liberadora de mão-de-obra no setor bancário. Trata-şe de identificar, cuidadosamente, o futuro papel da tecnocracia financeira, estamento que, a partir dos anos oitenta, de imples intermediário tecnopolítico, passa a uma posição pró-ativa no seio das corporações financeiras, tendendo seu poder a ampliar-se na exata medida em que evolui a complexidade gerencial do aparato tecnológico-administrativoe informacional, agora imprescindível na intermediação financeira e, portanto, no financiamento da acumulação de capital a longo prazo.

A eficácia em prever a evolução sócio-política deste estamento no bloco histórico, ora em gestação, determinará maior ou menor realismo e precisão e, consequientemente, maior ou menor sucesso, na concepção e implementação de um planejamento estratégico para o sistema financeiro.

\subsection{Eficiência Alocativa Versus Eficiência Distributiva}

O enfoque privatizante tenta resgatar a crença de que a acumulação seria incompatível com políticas de rendas redistributivas, consideradas, nesta ótica, como populistas ou simplesmente deniıigógicas.

A idéia de que a acumulação deve preceder, ou seguir-se ao processo distributivo encerra uma falsa dicotomia (Horn, 1985). Em verdade, a expansão do mercado interno e o desenvolvimento industrial são complementares e nunca mutuamente excludentes, particularmerite num contexto de encolhimento dos mercados internacionais. Os referenciais históricos asiáticos e europeus são particularmente ilustrativos da falácia dessa argümentação.

Em contraposição a este falso dilema, abre-se espaço, sob o enfoque estatizante, ao receio de que a acumulação de capital tecnológico implique 
liberação desordenada de mão-de-obra. Esta hipótese, legítima no curto prazo, torna-se altamente questionável quando se enfocam o médio e o longo prazos em um contexto de permanente evolução tecnológica, uma vez que as plantas industriais estariam comprometidas na ausência de multiplicadores tecnológicos apropriados para novos ciclos industriais, reforçando a dependência tecnológica e financeira do exterior, implicando provável sucateamento do parque industrial. Nesta perspectiva, o incremento tecnológico nãoé, necessariamente, liberador de mão-de-obra, mas sim a ausência de planejamento financeiro na utilização das adiçōes de capital por ele geradas.

O planejamento estratégico do sistema financeiro deve, portanto, contemplaro direcionamento dos fluxos financeiros advindos do incremento tecnológico, sendo inconcebível a análise em separado destes processos.

Com efeito, ambas as interpretações tendem a tratar a eficiência alocativa e a eficiência distributiva como departamentos estanques. Reinterpretando a questão sob a ótica financeira, encontraríamos a eficiência distributiva como complemento essencial da eficiência alocativa, se considerarmos o papel do sistema financeiro como viabilizador dos fluxos intersetoriais de poupança. Assim, a mútua excludência encontrada entre eficiência alocativa e eficiência distributiva só encontra sustentação se for ignorado o papel do sistema financeiro na articulação destes fluxos. Isto pode ser exemplarmente verificado nas experiências japonesa e alemã (Mckinnon, 1978, p.92), países onde os sistemas financeiros foram direcionados à lógica da acumulação industrial. No Japão, as unidades familiares proporcionam, regularmente, aproximadamente $50 \%$ da poupança líquida da economia, enquanto as empresas contribuem com $20 \%$ desta poupança e o Estado com o restante. Na Alemanha, a participação das unidades familiares não é menor, chegando a aproximadamente $60 \%$ da poupança líquida da economia.

Observa-se, portanto, que a polarização interpretativa, eclipsa, em boa medida, o papel do sistema financeiro levando a um terceiro viés interpretativo, centrado na dicotomia estoques versus fluxos.

\subsection{Estoques Versus Fluxos}

Ambos os enfoques concentram suas atenções na reestruturação dos estoques de capital disponíveis na economia.

A lógica privatizante leva à defesa quase incondicional da privatização do aparelho estatal. A lógica estatizante, por sua vez, leva à necessidade de rediscussão do sentido de propriedade, defendendo, eventualmente, com o mesmo critério de incondicionalidade a intocabilidade do aparelho estatal. Estas concepções quando transpostas à análise do sistema financeiro, reproduzem, na sua essência, boa parte dos vieses que lhes deram origem. 
A privatização, além de não apresentar solução de continuidade e não ser instrumento de controle da inflação, nãoé factível sob o ponto de vista econômicofinanceiro, principalmente se analisada à luz da própria teoria neoclássica (Dehesa, 1989), usualmente instrumentalizada para sua legitimação.

Por outro lado, a idéia de que seria técnica e politicamente possível alterar a atual composição dos ativos do país, quer seja pelo confisco planejado de estoques de capital, quer seja pelo balizamento fiscal, ignora por completo a inserção capitalista do Brasil no cenário econômico mundial e o alcance jurídico e legal de tais medidas em um contexto de plena vinculação aos euromercados.

Entre outros aspectos, tais alterações de caráter exclusivamente patrimonial, no máximo, consolidariam a internacionalização dos capitais brasileiros já articulados nos mercados offshore, cujas megacifras são difíceis de estimar (Wachtel, 1988), em face do amplo leque de dispositivos de tranferências intrabancárias e empréstimos interbancários não monitoráveis pelos bancos centrais.

É o nosso entendimento que a reorganização econômica do país passa pela reorganização do seu sistema de fluxos de capitais, sendo o estoque de capital, já consolidado cultural e institucionalmente, variável secundária, caso se pretenda elaborar um projeto de longo prazo política e economicamente factível.

A reorganização dos fluxos de capitais implica, de imediato, releitura do papel do sistema financeiro brasileiro, abandonando-se o viés estoque-fluxo, que já se constitui hoje em uma obsessão cultural terceiro-mundista, de caráter supraideológico. Paradoxalmente, esta obsessão termina por direcionar o enfoque analítico da discussão à conveniência ou não de maior ou menor controle dos mercados monetários e cambiais, via monitoramento das taxas de juros e os mais diversos balizamentos tributários.

Negligencia-se, assim, a discussão sobre a pertinência e eficácia das estruturas de prazo e retorno dos instrumentos financeiros vigentes nos mercados de crédito e de capitais. Mais do que isso, fica colocada em um segundo plano a reorganização dos mercados bursáteis, extremameıte distanciados, na sua volatilidade e inconsistência, de seu papel primordial de proporcionar liquidez aos papéis que financiam as empresas de capital aberto. Com efeito, os portfólios das bolsas de valores nacionais, concentrados setorialmente em torno das ações de grandes estatais e dos grandes conglomerados financeiros, funcionam hoje como apêndice especulativo da indústria bancária (estatal e privada), controladora direta ou indireta (via fundos de previdência) da maior parte destes ativos.

A partir destas colocações passarem agora a uma sucinta exposição, balizadora de nossa contribuição para a discussão, centrada na reorganização das superestruturas de investimentoe poupança do sistema financeiro, ao encontro das sínteses obtidas a partir de nossa análise dos vieses interpretativos e da digressão sobre seus referenciais. 


\section{OUTROS REFERENCIAIS}

A idéia de novos referenciais não deve, sob nenhuma hipótese, ser aqui interpretada como pretensão a qualquer perspectiva conceitual nova, alicerçada em um terceiro paradigma. Pelo contrário, nossa perspectiva é, tão somente, a partir das críticas propostas, passar a propostas críticas, que permitam a construção de alternativas plenamente inseridas nos paradigmas analíticos disponíveis, subsumidos, em nosso caso, às duas vertentes explicitadas. Aparentemente, algumas destas propostas apresentarão conciliaçōes conceituais, embora, em realidade, constituam apenas o resgate de concepções e idéias encontradas no corpo das discussões entre as duas vertentes, marginalizadas em boa medida pelas limitações de nossa cultura organizacional.

Inicialmente, destacamos os referenciais sugeridos a partir dos vieses analisados. Da dicotomia eficiência microeconômica versus eficiência mácroeconômica obtemos a leitura da capacidade ociosa e do novo papel da tecnocracia financeira; da dicotomia eficiência alocativa versus eficiência distributiva obtemos a leitura da evolução tecnologica e da liberação de mão-deobra; em estoques versus fluxos obtemos a discussão sobre as novas estruturas de prazo e retorno e o resgate dos mercados bursáteis.

Com estes referenciais, passaremos agora à sugestão de uma rationale alternativa que se propõe a contemplar algumas das lacunas percebidas em nossa leitura dos vieses interpretativos das duas vertentes. São apresentados alguns exemplos de elementos que comporiam um planejamento estratético sob a égide dessa rationale. Nossa concepção divide-se, para fins de simplificação da exposição, em dois níveis analíticos, respectivamente, a organização do investimento e a organização da poupança.

\subsection{A Organização do Investimento}

A ênfase fundamental centrar-se-á na exposição de propostasque viabilizam a mudanģ a de enfoque da estrutura de retornos das taxas de juros para a estrutura de prazos das taxas de juros. A perspectiva organizacional é a indução de novas tecnologias e instrumentos financeiros, que ccmpatibilizem a orientação macroeconômica com liberdade negocial.

Notadamente, as operações ativas de curto prazo constituem o nicho comercial mais atraente para os bancos. Nossa perspectiva é transferir-se a eficiência alocativa já consolidada nas operações de curto prazo para estruturas de prazo compaíveis com a perspectiva da acumulação de capital a longo prazo.

Com esta perspectiva, a organização do investimento poderia alicerçar-se na articulação de dois instrumentos fundamentais, a saber:

- O contingenciamento de prazos e

- O encorajamento de produção seletiva. 


\section{O Contingenciamento de Prazos}

Em uma política de contingenciamento de prazos, o volume de operações de curto prazo seria institucionalmente vinculado ao atingimento de metas de operações de longo prazo. Assim, por exemplo, seria permitido a instituição financeira operar livremente (em prazos e taxas) com $70 \%$ do volume de aplicações, desde que fossem efetivamente realizadas operações de longo prazo com taxas prefixadas, com os $30 \%$ restantes. Em outras palavras, necessariamente, $30 \%$ de todas as operações seriam de longo prazo. Três aspectos precisam sčr salientados:

10 "Efetivamente", no parágrafo acima, significa que não basta realizar-se a oferta de crédito, mas sim a operação de crédito, uma vez que não se pretende estabelecer tetos para as taxas de juros. Do contrário, as instituições financeiras contornariam o contingenciamento, ofertando expressivos volumes de crédito a longo prazo que não teriam demanda em função das taxas elevadas.

$2^{\circ}$ Os prazos e proporşñes entre operações compulsórias e não compulsórias submeter-se-iam às determinações da política governamental, ficando, entretanto, assegurada a liberdade na fixação das taxas de juros.

3- A prefixação de taxas é fundamental para a alteração das expectativas inflacionárias $\mathrm{Na}$ ausência de demanda de crédito de longo prazo, em função da fixação de taxas em níveis elevados, a lucratividade operacional de curto prazo das instituições financeiras estaria comprometida. Por outro lado, uma oferta de crédito com taxas de lucro superiores às do sistema industrial inviabilizaria a imolementação dos projetos a serem financiados. Em um cenário de posições contratadas prefixadas com taxas relativamente baixas é evidente que o próprio sistema financeiro teria extremo interesse na manutenção das taxas de inflação em nívcis, no mínimo, inferiores às taxas de retorno para os spreads projetados. Ao contrário do que agora ocorre, taxas altas de inflação obstariam a lucratividade de curto prazo das instituições financeiras, alterando a circularidade inflacionária e reduzindo os custos do setor industrial.

\section{O Encorajamento da Produção Seletiva}

Dentre as alternativas de ericorajamento da produção seletiva, existe a possibilidade e orientur-se as operações a longo prazo, no sentidode compartimentálas em prioridades específicas. Assim, por exemplo, 25\% de todas as operações de longo prazo seriam compulsoriamente aplicadas no financiamento da indústria de informática, $20 \%$ na metal-mecânica, $15 \%$ na construção civil etc.

Integra-se a esta perspectiva a estruturação compulsória de parcela das operações em projetos ligados à pesquisa científica necessariamente vinculados 
às instituições universitárias. Concebe-se, assim, a possibilidade de viabilização da ciência básica via financiamento das ciências aplicadas, orientadas pela lógica empresarial.

Saliente-se que ficaria sob controle estatal somente a fixação das estruturas de prioridades, mas não a decisão de investimento, uma vez que as instituições financeiras escolheriam livremente, dentro das faixas determinadas, as empresas e projetos a serem financiados. Embora estruturado em termos distintos dos aqui propostos, o encorajamento da produção seletiva foi a alternativa organizacional implementada pelo Japão no pós-guerra (Fujita, 1964).

Garantindo-se a liberdade na decisão de investimento, captura-se a eficiência alocacional já consolidada na indústria bancária, redirecionando-a, todavia, para a consecução de políticas industriais apropriadas ao planejamento estratégico a ser implementado.

\subsection{A Organização da Poupança}

Enqưuanto na organização do investimento encontramos elementos que buscam conciliar a eficiência macro e microeconômica, a organização dos instrumentos de poupança enseja a possibilidade de alavancar-se essa conciliação, integrando-se instrumentos que resgatam os fluxos econômicos sem deixar de assegurar, todavia, alternativas racionais para o conflito distributivo que normalmente lastreia o rationale da organização da poupança no Brasil.

Dentro da mesma perspectiva, dois instrumentos basilares poderiam ser utilizados para a reorganização da poupança com fins ao financiamento da acumulação de capital a longo prazo:

- o salário-poupança

- o lucro-poupança

A organização do mecanismo do salário poupança insere-se num contexto maior, o da organização de uma política de rendas. A idéia básica é a fixação de uma política salarial que, necessariamente, proporcione ganhos reais a todas as faixas salariais, sendnque parcelas deste ganho real, nas faixas salariaismais altas, seriam alocadas compulsoriamente em instrumentos de captacão nos mercados de crédito e nos instrumentos disponíveis, ou a serem criados, nos mercados de capitais, vinculados, naturalmente, a estruturas de prazos compatíveis com os períodos médios normalmente necessários à maturação de projetos industriais.

Cabe salientar que o salário-poupança compulsório é fixado sobre ganhos reais institucionalmente determinados para todas as faixas salariais acima do salário mínimo, não sendo aplicado para ganhos reais não institucionalmente determinados, obtidos em dissídios coletivos, garantindo, portanto, a livre nego- 
ciação a partir de determinadas faixas de renda, normalmente associadas a categorias tradicionalmente mais organizadas e com maior densidade sindical.

Da mesma forma, parcelas do lucro das empresas seriam compulsoriamente alocadas em duas modalidades de investimento de longo prazo; reinvestimento tecnológico orientado na própria empresa, e investimentos em títulos de longo prazo, disponíveis ou a serem criados nos mercados de capitais, constituindo-se em lucro-poupança.

Ambos os mecanismos de poupança compulsória são pensados de forma articulada à necessidade de conciliação macro-micro explicitada no contingenciamento das estruturas de prazos. Neste sentido, busca-se um incremento da integração operacional, atualmente residual, dos mercados de crédito e de capitais. Esta integração, que hoje consolida-se apenas em nível patrimonial, revigoraria a atuação dos bancos de investimentos e dos mercados bursáteis que, alterando seu caráter e escala, transformar-se-iam nos principais agentes do financiamento das empresas de capital aberto. Este reordenamento dos fluxos de capitais, onde a poupança privada financia o capital privado, sem a absorção do risco pelo Estado, implica substanciais ganhos na produtividade do capital financeiro, ao encontro de nossa percepção inicial da capacidade ociosa do sistema financeiro.

Altera-se a leitura da produtividade do sistema financeiro, como elemento não mais traduzível apenas quantitativamente através de indicadores econômicofinanceiros, mas, sobretudo, auferivel qualitativamente pelo impacto de suas operações no contexto da acumulação de capital a longo prazo.

Finalmente, cabe ressaltar que a implementação do conjunto destas medidas não poderia ser dissociada de uma ampla reforma no atual sistema jurídicocontábil, que desse transparência e precisão aos demonstrativos das empresas, particularmente aquelas ligadas ao segmento financeiro, de maneira a permitir o controle de seus fluxos de capitais e não somente a análise estática disponível nos balanços e balancetes, que pouco expressam sobre a realidade financeira dinâmica.

\section{CONCLUSÃo}

Oesboço apresentado dos elementos de um projeto alternativo para o sistema financeiro aproveita as estruturas já existentes, relativamente avançadas sob o ponto de vista tecnológico e operacional, alterando, todavia, a estratégia de sua superestrutura organizaciona! Além disso, reorienta o papel do sistema, num trade-off aceitável sob o ponto de vista político e econômico, entre lucro de curto prazo e lucro no longo prazo. Observe-se que o reordenamento dos fluxos não implica transformações brutais na composição dos estoques de ativos, sendo passível de negociação dentro do contexto institucional e sócio-cultural existente. 
Quanto à dicotomia, eficiência alocativa versus eficiência distributiva, contempla-se a eficiência alocativa microeconômica ao deixar a decisão final de investimento a critério dos analistas vinculados às instituições financeiras $e$ empresas financiadas, não violando, portanto, a textura competitiva, resgatando, sobretudo, a noção de risco do investimento de longo prazo, que não mais será absorvido pelo Estado.

A eficiência alocativa macroeconômica fica assegurada pela orientação estatal quanto à estrutura de prazos e prioridades, subentendendo-se que a configuração desta estrutura deve subordinar-se a um planejamento estratégico de longo prazo, que enfoque, principalmente, o resgate tecnológico do setor industrial. Em síntese, a decisão macroeconômica de investimento fica a cargo do Estado e a decisão microeconômica a cargo do setor privado.

A eficiência distributiva, bem como a reestruturação do mercado interno ficam asseguradas pela vinculação da política de rendas à política de acumulação de capital a longo prazo, tornando-as, até certo ponto, complementares.

O conjunto destas medidas far-se-ia sentir na não-intermediação do Estado no financiamento da estrutura industrial, permitindo, indiretamente, o reequacionamento da dívida pública, abrindo espaço, por exemplo, ao estabelecimento de uma política de investimentos públicos de caráter redistributivo. Adicionalmente, $o$ aumento do emprego e da atividade econômica, concomitante à articulação de uma estrutura tributária progressiva, aumentaria substancialmente as possibilidades de financiamento endógeno do setor público, livrando-o da ciranda financeira.

Neste contexto, a reversão das expectativas inflacionárias é tratada aqui como um problema estrutural, só alcançável a médio prazo. Isto não impede, entretanto, que sejam conjugadas políticas fiscais e monetárias compatíveis com a reestruturação proposta, visando ao controle da moeda, factível em função da gradualidade proporcionada pelo redimensionamento das estruturas de prazo das taxas de jurose pela mudança doreferencial de acumulaçãoda cultura organizacional do capital.

Conclusivamente, o resgate do planejamento estratégico do sistema financeiro permite que se rompa a atual circularidade do financiamento empresarial no Brasil, onde os bancos financiam o Estado que, por sua vez, financia a acumulação de capital a longo prazo. Resgata-se, sobretudo, a lógica de risco-retorno e a dinâmica da atividade capitalista, voltando o lucro financeiro a constituir-se em parte do lucro industrial, e não mais em seu obstáculo maior. 


\section{BIBLIOGRAFIA}

DEHESA, Guilherme de La. Os Vários Fatores que Influenciam na Hora da Privatização - Gazeta Mercantil. 15 junho 1989.

FUJITA. Masahiro. Long Term Finance in Post-War Japan. Kobe Economic and Business Review, v.11, p.93-111, 1964.

HORN, Carlos Henrique. Sobre a Dependência de Poupança Extema: A Interpretação Conservadora do Endividamento Externo Brasileiro. Análise Econômica Porto Alegre: FCE/FRGS. Ano 3, n 5, p.39-52, nov. 1985.

MCKINNON, Ronald I A Moeda e o Capital no Desenvołvimento Econômico. Rio de Janeiro: Interciência, 1978.

MOTTA, Paulo César. A Redefinição dos Negocios Bancários a Partir das Tecnologias de Automoção. Revista Brasileira de Mercado de Capitais, v.13, $n^{2} 39$, p.109-121, abr/jun.1987.

PEREIRA, Eduardo Novo Costa \& NUNES, Rosaline Phillips. Sistema Financeiro Nacional: Uma Avaliação Sobre o seu Desenvolvimento Recente. Revista Brasileria de Mercado de Capitais, v. 10, $\mathbf{n}^{2} 32$, p 293-302, out./dez. 1984

TAVARES, Miguel Dirceu Fonseca. Trajetoria para a Reforma Financeira. Rio de Janeiro: Revista Brasileira de Mercado de Capitais, v. 10, $n^{9}$ 32, p. 361-385, out /dez. 1984.

WACHTEL, Howard M. Os Mandarins do Dinheiro. As Origens da Nova Ordem Econômica Supranacional. Rio de Janeiro: Nova Fronteira, 1988.

\section{ABSTRACT \\ BPAZILIAN FINANCIAL SYSTEM: A PROPOSAL FOR DISCUSSION}

This article focuses at different afproaches concerning the financial system's role on the long term capital accumulation in the Brazilian economy. It reappraises what is here understood as interpretative biases established by the two main trends, such as: privatization defenders and state-ownership supporters, in an effort to contribute to the ongoing structuring of other referentials for the discussion over the perspectives of fered by the financial system to reorganization of long term capital accumulation planning in the Brazilian economy 